\title{
Characteristics Predicting the Outcome in Individuals with Diabetic Foot Ulcerations (P61)
}

\section{$\underline{\text { C.FORMOSA }}^{1}$ LOURDES VELLA ${ }^{2}$}

1* University of Malta (Corresponding author -

Cy nthia.formosa@um.edu.mt)

\section{Introduction}

Foot ulcerations are one of the most feared complications for both people with diabetes and health care providers due to their negative impact on lives resulting in overall poor prognosis of the disease, leading to long periods of hospitalization and substantial health care costs[1].

Data regarding factors which could influence ulcer healing is varied [2]. The ability to predict whether a diabetic foot ulcer is following versus not following a healing trajectory could dramatically alter patient outcomes by reassessing the wound condition and considering an alternative treatment regimen [3].

The aim of this study was to determine patient and ulcer characteristics which predict wound healing in patients living with diabetes

\section{Methodology}

A prospective observational study was conducted on 99 subjects presenting with a diabetic foot ulceration. Patient and ulcer characteristics were recorded. Patients were followed up to a maximum of 1 year.

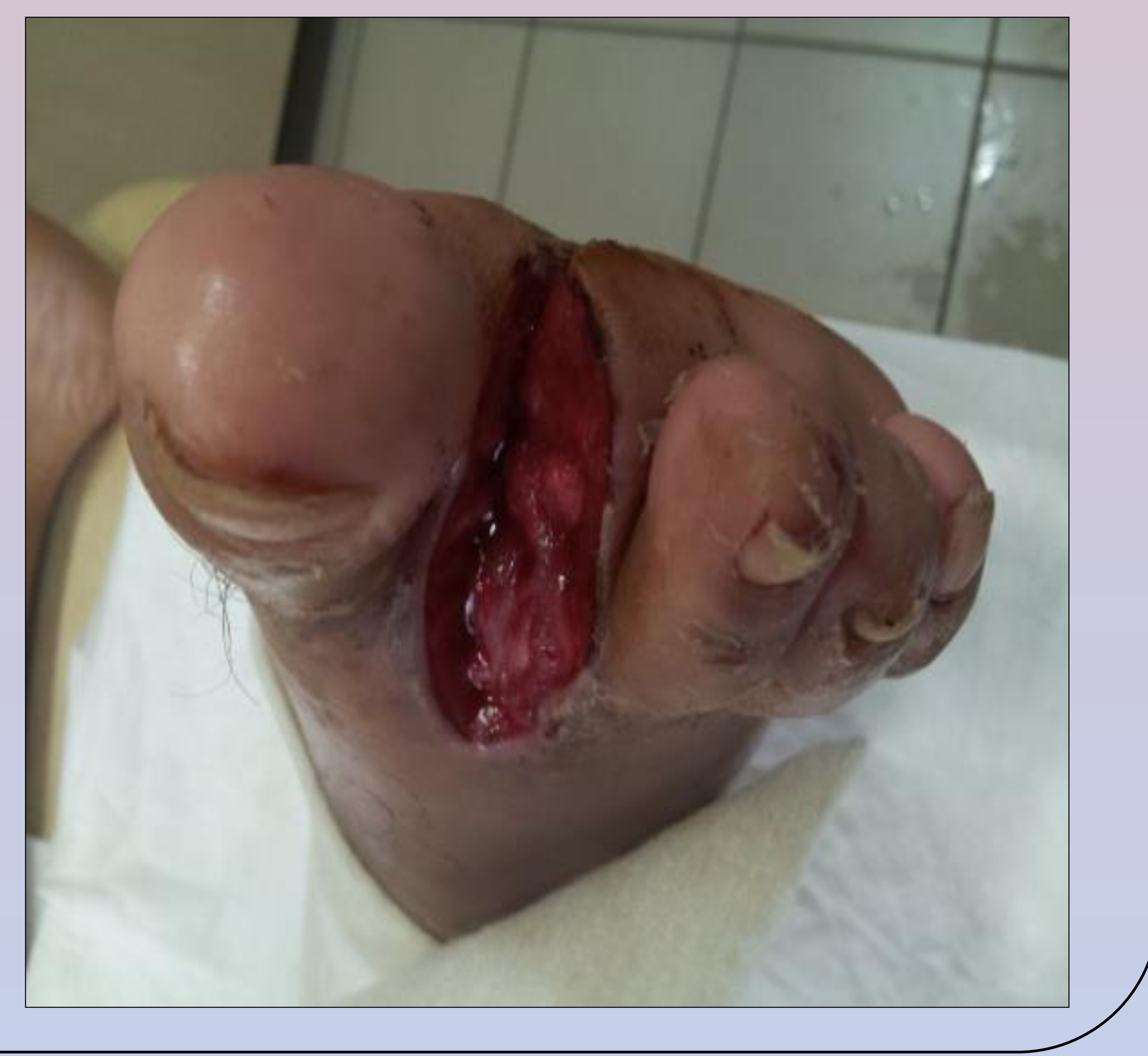

\section{Results}

After 1 year of follow-up, ulcer characteristics were more predictive of ulcer healing than patient characteristics. Seventy-seven per cent of ulcers healed and $23 \%$ had not healed.

Independent predictors of non-healing were ulcer stage $(p=0.003)$, presence of biofilm $(p=0.020)$, presence of infection $(p=0.022)$ and ulcer depth $(p=0.028)$ in the study group.

Although this study demonstrated that the baseline HBA1c reading at the start of the study was not a significant predictor of foot ulcer outcome [ $p=0.603$, resolved vs amputated], however upon further statistical analyses, when $\mathrm{HbA1c}$ was compared to the time taken for complete ulcer healing [n=77], it proved to be significant $[p=0.009]$.

\section{Conclusion}

The factors influencing healing are ulcer stage, presence of biofilm and ulcer depth. These findings have important implications for clinical practice especially in an out-patient setting. Prediction of outcome may be helpful for healthcare professionals in individualizing and optimizing clinical assessment and management of patients. Identification of determinants of outcome could result in improved health outcomes, improved quality of life and lesser diabetes related foot complications.

\section{References}

1. Boulton AJM, Vileikyte L, Ragnarson-Tennvall G, \& Apelqvist J. The global burden of diabetic foot disease. Lancet 2005; $366: 1721-1725$.

2. Apelqvist J, Bakker K, Van Houtum WH, \& Schaper, NC. Practical guidelines in the management and the prevention of the diabetic foot, based upon the International Consensus on the Diabetic Foot. Diabetes/Metabolism Research and Reviews 2008; 24(1): S181-S187.

3. Boulton AJ, Kirsner RS, Vileikyte L. Clinical practice. Neuropathic diabetic foot ulcers. The New England Journal of Medicine2004 351(1), 48-55.

Publication - This paper is currently in press in the Journal of the American Podiatric Medical Association (JAPMA) 